\title{
Numerical simulation of reservoir fluctuation effects on the nonlinear dynamic response of concrete arch dams
}

\author{
M. A. Hariri Ardebili \& H. Mirzabozorg \\ Department of Civil Engineering, \\ K. N. Toosi University of Technology, Iran
}

\begin{abstract}
Fluid-structure interaction problems occur in many engineering structures, such as dams, gates, offshore structures, storage tanks, piping systems, etc. Analysis of such interaction problems is important for the safe and economic design of future structures and the safety and performance evaluation of present ones. In the present study, reservoir fluctuation effects on the nonlinear dynamic response of concrete arch dams are investigated. The structure nonlinearity is originated from material nonlinearity due to tensile cracking and compression crushing of mass concrete using the William-Warnke failure surface in principal stress state (Smeared Crack Model). The reservoir is assumed to be compressible and foundation rock is modeled as a mass-less medium. The DEZ concrete arch dam in Iran, with a height of $203 \mathrm{~m}$, is selected as the case study. The system is executed using records based on the response spectrum of the dam site. It is found that fluid-structure interaction has significant structural effects on the system such that, when the reservoir level is increased, almost all structural responses of the dam body, such as crest displacement, velocity and acceleration, decrease until a special level and growth is significantly made for reservoir maximum level in the linear model. In addition, principal stresses on upstream and downstream faces increase significantly with reservoir dewatering. On the other hand, responses of the dam in the nonlinear model have special intricacies, but the extension of cracked areas in both upstream and downstream faces develop meaningfully by decreasing the reservoir water level and there is good argument between stress results in the linear and nonlinear models.
\end{abstract}

Keywords: concrete arch dam, fluid-structure interaction, reservoir fluctuation effect, smeared crack model. 


\section{Introduction}

Interaction between dams and impounded water is one of key factors affecting the seismic response of arch dams during earthquakes. When the dam-reservoir system is subjected to an earthquake, hydrodynamic pressure in excess of hydrostatic pressure occurs on the upstream face due to vibration of the dam body and water in the reservoir. The magnitude of hydrodynamic pressure effect on the response of arch dams depends on the water level in the reservoir, which is governed by the reservoir operation regime. Sometimes the reservoir may be dewatered to visit the upstream face or to repair probable damages or because of drought and it has been found that these states can considerably affect the response of arch dams during earthquakes. The importance of hydrodynamic effects on the behavior of arch dams subjected to earthquake ground motions has long been recognized by investigators, such as Chopra [1], Chwang [2], Fok and Chopra [3], Hung and Chen [4], Fahjan et al. [5]. They studied dam-reservoir systems with different geometrical features of the dam body and the pertinent reservoir. In Fok and Chopra's studies, complex frequency functions were used to define dam-reservoir interactions and concrete material was assumed to be linearly elastic. They found that hydrodynamic pressure plays an important role on the dynamic response of arch dams. In these studies, the reservoir was generally considered to be empty or full. Proulx et al. [6] investigated experimentally and numerically the variation of resonant frequencies of EMOSSON arch dam for four different water levels. Akkose et al. [7] studied reservoir water level effects on the nonlinear dynamic response of arch dams. In their investigation, concrete is idealized as elasto-plastic material using the Drucker-Prager model and the reservoir was modeled with Lagrangian fluid finite elements. They found that reservoir water level effects must be considered in the nonlinear analysis of arch dams.

There are several approaches to simulate the stress-strain relationship of mass concrete under various stress states. In this regard, theories based on plasticity and fracture mechanics approaches have been developed and used in most engineering analyses. In addition, several researches have been conducted to study the dynamic behavior of concrete arch dams. Kuo [8] suggested an interface smeared crack approach to model contraction joints and used this technique for the dynamic analysis of arch dams. Hall [9] proposed a simple smeared crack model to simulate contraction joints, while diagonal cracking is neglected in his work. Espandar and Lotfi [10] applied non-orthogonal smeared crack and elasto-plastic approaches to the Shaheed Rajaee arch dam in Iran. Mirzabozorg et al. [11] utilized a damage mechanics approach to conduct seismic nonlinear analysis of concrete gravity dams in 2D space, including damreservoir interaction effects. In 2005, Mirzabozorg and Ghaemian [12] developed a model based on the smeared crack approach in 3D space. In their work, they analyzed 3D models, including dam-reservoir interaction effects, and considered the nonlinear behavior of the structure.

In the present study, reservoir level fluctuation effects on the nonlinear seismic response of a high arch dam, including dam-reservoir-foundation 
interaction, is investigated utilizing the Eulerian approach in the fluid domain and the Lagrangian approach in the solid domain. The dam body is modeled, defining concrete material properties and considering the smeared crack method entitled NL-SCM, and dam-reservoir-foundation interaction is taken into account. In the conducted analyses, the height of water in the reservoir is considered in four various levels so that in the first analysis $28.9 \%$, in the second $52.1 \%$, in the third $79.9 \%$ and in the last one $96.9 \%$ of the total height of the dam body is filled in order to study responses of the modeled system.

\section{Constitutive models for concrete material nonlinearity}

In theories based on continuum crack, the fracture is idealized to propagate as a blunt front smeared over an entire element or a certain band width of the element. After initiation of the fracture process, determined by a suitable constitutive model, the pre-crack material stress-strain relation is replaced by an orthotropic relation with a material reference axis system aligned with the fracture direction. One of the most important branches of continuum crack is the nonlinear - smeared crack model (NL-SCM), which considers concrete nonlinear characteristics.

The behavior of concrete elements is assumed to be linear elastic until it reaches ultimate strength (Figure 1) and the elasticity modulus of concrete is considered as the average, E, instead of the linear actual, $\mathrm{E}_{0}$. Stress increases linearly along with an increase in strain. In this step, each reloading of elements

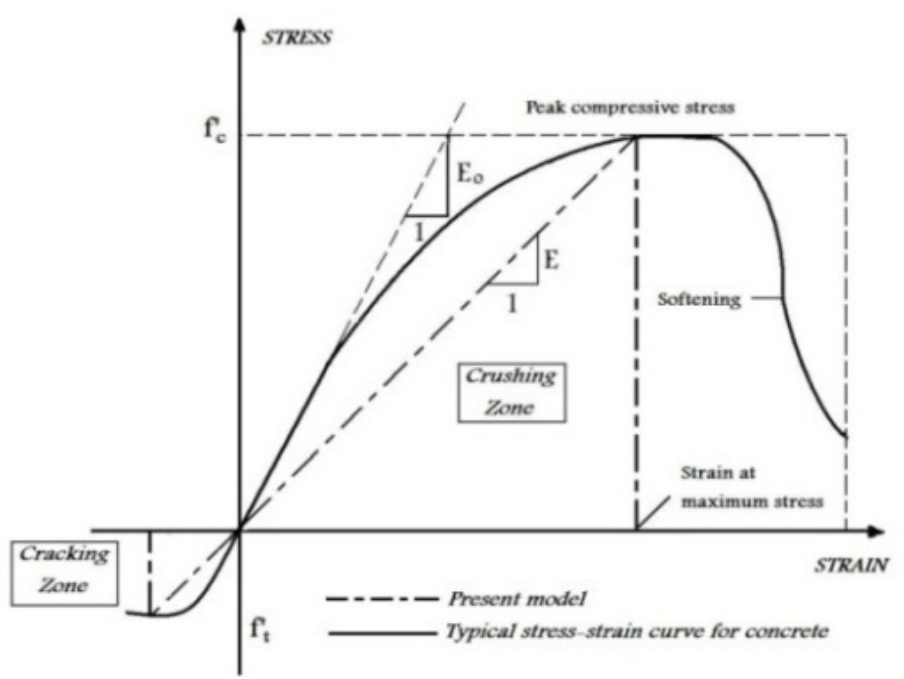

Figure 1: Typical uniaxial compressive/tensile stress-strain curve for concrete. 
leads to elastic returning of strain. The tension failure of concrete is characterized by a gradual growth of cracks, which join together and finally disconnect larger parts of the structure. It is a usual assumption that forming cracks is a brittle process and the strength in the tension-loading direction abruptly goes to zero after big cracks.

In the utilized model, cracking occurs based on the William-Warnke 5parameter failure model. According to this theory, cracking occurs when a combination of principal stresses in any direction lies outside the biaxial failure surface. After cracking, the elastic modulus of the element is set to zero in the direction parallel to the principal tensile stress direction. In this model cracking is permitted in three orthogonal directions at each integration point. When cracking occurs at an integration point, the stress-strain relation is modified by defining a weak plane normal to the crack direction, which is unable to endure any tensile stresses.

\section{Finite element formulation of reservoir}

Hydrodynamic pressure distribution within a reservoir is governed by the pressure wave equation. Assuming water is linearly compressible and neglecting viscosity, the small-amplitude irrotational motion of water is governed by the $3 \mathrm{D}$ wave equation given as:

$$
\nabla^{2} P(x, y, z)=\frac{1}{c_{\bullet}{ }^{2}} \ddot{P}(x, y, z, t)
$$

where $\mathrm{P}$ is hydrodynamic pressure and $\mathrm{c}_{0}$ is the velocity of the pressure wave in the water.

For earthquake excitation, conditions at the boundaries of dam-reservoir, reservoir-foundation, reservoir-far-end and reservoir-free-surface as, shown in figure 2 , are governed as given in following sections.

\subsection{Dam-reservoir boundary condition}

At the surface of fluid-structure, there must be no flow across the interface. This is based on the fact that the face of concrete dams is impermeable.

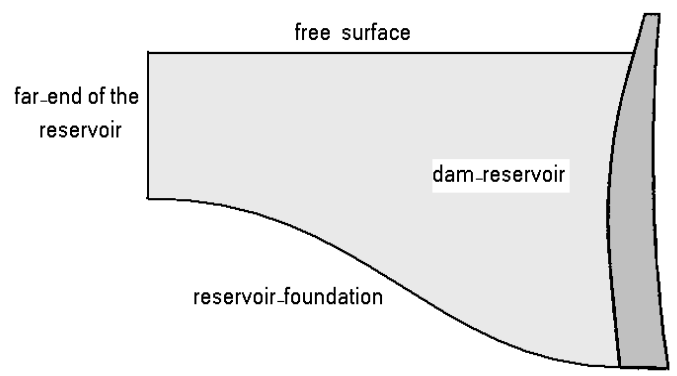

Figure 2: Boundary conditions for dam-reservoir-foundation. 


$$
\frac{\partial P(x, y, z, t)}{\partial n}=-\rho a^{s}{ }_{n}(x, y, z, t)
$$

in which $\mathrm{a}_{\mathrm{n}}^{\mathrm{s}}$ is normal acceleration of the dam body on the dam-reservoir interface and $\mathrm{n}$ is the normal vector on the face. The superscript $\mathrm{s}$ refers to structure.

\subsection{Reservoir-foundation boundary condition}

If there is no energy absorption on the reservoir bottom and sides, the same boundary condition represented in eqn (2) is used. The reservoir bottom absorption effect can be implemented with eqn (3).

$$
\frac{\partial P(0, t)}{\partial n}=-\rho a_{n}(t)+q \frac{\partial P(0, t)}{\partial t}
$$

where $\mathrm{q}$ is the admittance coefficient and the relation between $\mathrm{q}$ and the wave reflection coefficient, $\alpha$, is expressed as:

$$
\alpha=\frac{1-q c}{1+q c}
$$

\subsection{Free-surface boundary condition}

In high reservoirs, surface waves are negligible and hydrodynamic pressure on the reservoir surface is taken as zero.

\subsection{Reservoir-far-end boundary condition}

For modeling far-end truncated boundary, viscous boundary called as Sommerfeld boundary condition is utilized given as eqn (5).

$$
\frac{\partial P}{\partial n}=-\frac{1}{c .} \frac{\partial P}{\partial t}
$$

\section{Numerical simulation of the model}

DEZ dam is a high double curvature arch dam with a peripheral joint separating the dam body from its concrete saddle structure (PULVINO foundation). Its total height (maximum height above the foundation) is $203 \mathrm{~m}$ and the height of the main body is $186 \mathrm{~m}$. Thickness of the dam at crest is $4.5 \mathrm{~m}$ and its maximum thickness at base is $21 \mathrm{~m}$. 

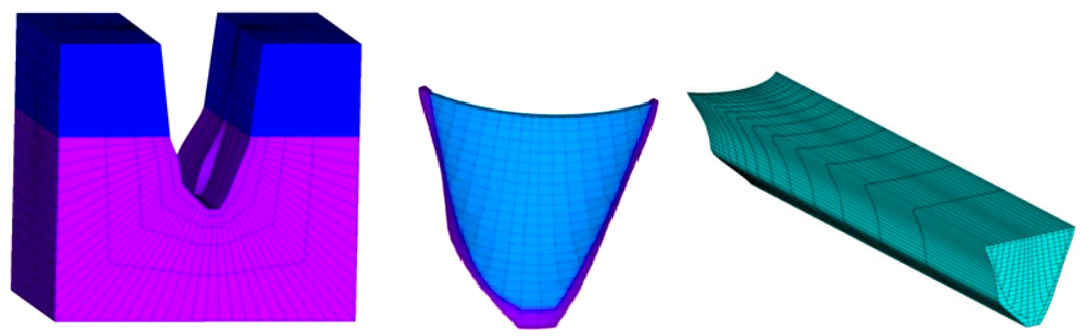

Figure 3: $\quad$ Finite element model of the dam, foundation and reservoir.

Finite element idealization prepared for dam, foundation rock and reservoir is presented in figure (3). Model consist 792 8-node solid elements for modeling concrete dam and saddle and 3770 elements for modeling foundation region. In addition, reservoir is modeled using 3660 Eulerian fluid elements.

Isotropic elasticity of mass concrete in static and dynamic conditions is 40GPa and 46GPa and Poisson's ratio are 0.2 and 0.14 , respectively. Density of mass concrete is $2400 \mathrm{Kg} / \mathrm{m}^{3}$. Uniaxial crushing and cracking strength for mass concrete under static loads are $35 \mathrm{MPa}$ and $3.4 \mathrm{MPa}$ and under seismic loads are raised to $36.5 \mathrm{MPa}$ and $5.1 \mathrm{MPa}$ respectively. Also, isotropic elasticity of foundation rock in saturated and unsaturated regions is reported as $13 \mathrm{GPa}$ and $15 \mathrm{GPa}$. Furthermore, reservoir water density is assumed $1000 \mathrm{~kg} / \mathrm{m}^{3}$, sound velocity is $1440 \mathrm{~m} / \mathrm{s}$ in water and wave reflection coefficient for reservoir around boundary is taken as 0.8 .

\section{Loading history}

Applied loads are dam body self-weight, hydrostatic pressure in various water levels and earthquake load. It is worth noting that thermal loads is not considered in the current article because of the main object of the study which is considering fluctuation effects of the reservoir water level. The $\beta$-Newmark method is utilized to solve the coupled nonlinear problem of dam-reservoir-foundation model.

The system is excited at foundation boundaries using TABAS earthquake records. Total time duration of earthquake is $48.9 \mathrm{~s}$. For specifying significant duration of excitation, Arias intensity on Husid diagram was used and time interval between $10 \%$ and $80 \%$ of Arias intensity (totally $70 \%$ ) was selected. With this method significant time duration is obtained to be 10s (as shown in figure 4). Moreover structural damping is taken to be $10 \%$ of critical damping.

\section{Discussion of results}

Considering great importance of natural vibration modes, 30 first periods of dam-reservoir-foundation system in four different water levels was extracted. As seen in figure 5, natural period grows associated with reservoir impounding 
which is because of added mass to the system. Differences between modes are meaningful for ten first modes. Water levels in reservoir are considered as 56, 101,155 and $188 \mathrm{~m}$ that stand to level I, level II, level III and level IV to investigate reservoir level fluctuation effects on dynamic responses of the selected arch dam.

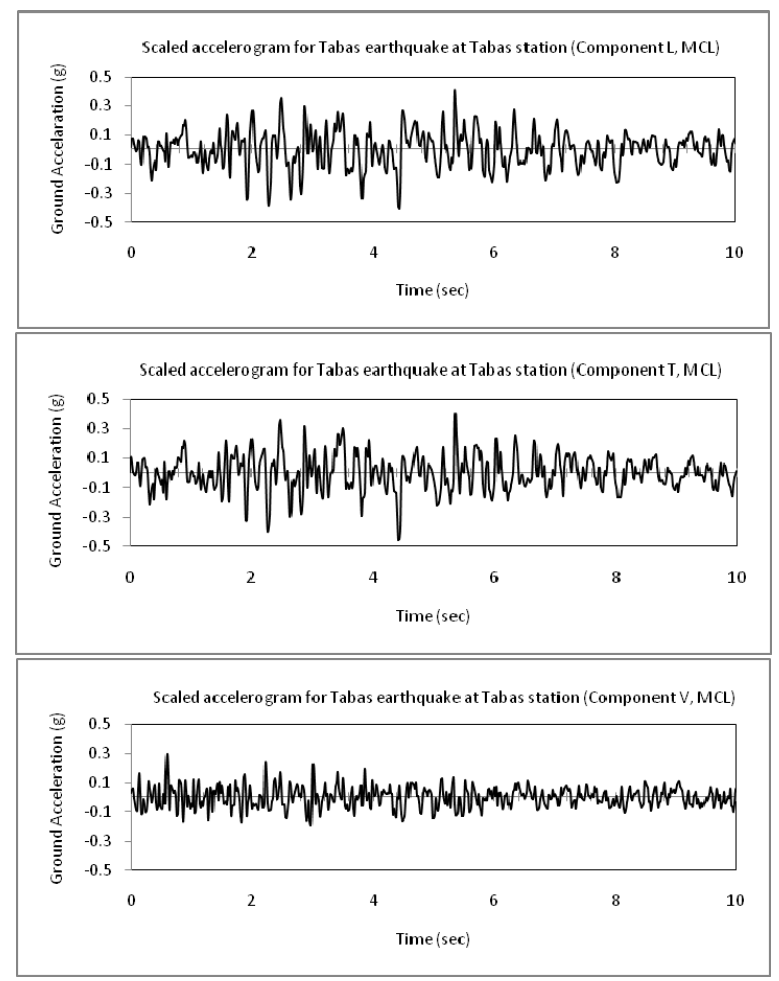

Figure 4: TABAS earthquake in TABAS station.

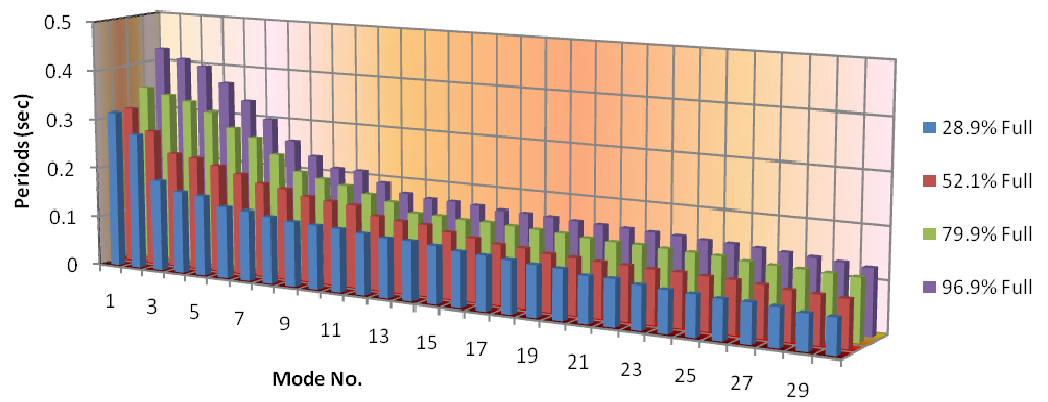

Figure 5: Comparison of dam periods at four different reservoir levels. 

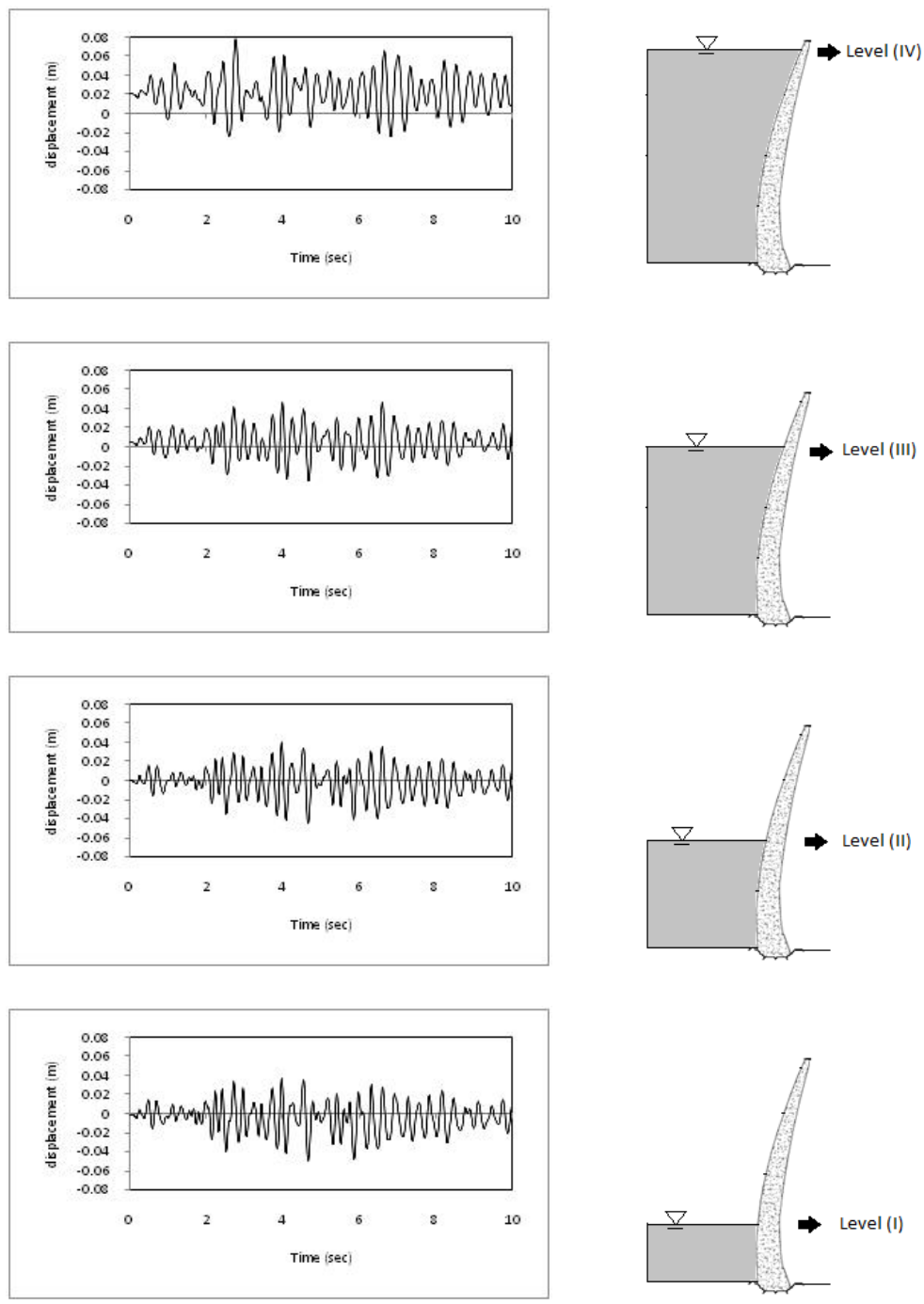

Figure 6: Time-history of US/DS displacement for the center of the crest.

\subsection{Crest displacement}

Time-history of crest displacement at central cantilever in four considered reservoir water levels is shown in figure 6. As can be seen, when the reservoir level is decreased, crest displacement shifts toward upstream direction. The crest experiences maximum displacement in downstream direction when the reservoir level is set to be at level IV. 
Table 1: Absolute max velocity of crest points in the stream direction.

\begin{tabular}{|cccc|}
\hline & $\begin{array}{c}\text { Center point } \\
(\mathrm{m} / \mathrm{s})\end{array}$ & $\begin{array}{c}\text { Left quarter point } \\
(\mathrm{m} / \mathrm{s})\end{array}$ & $\begin{array}{c}\text { Right quarter } \\
\text { point }(\mathrm{m} / \mathrm{s})\end{array}$ \\
\hline Level (IV) & 1.093 & 0.779 & 0.766 \\
\hline Level (III) & 1.064 & 0.697 & 0.700 \\
\hline Level (II) & 1.087 & 1.133 & 0.832 \\
\hline Level (I) & 1.157 & 1.142 & 0.850 \\
\hline
\end{tabular}

Table 2: $\quad$ Absolute max acceleration of crest points in the stream direction.

\begin{tabular}{|cccc|} 
& $\begin{array}{c}\text { Center point } \\
\left(\mathrm{m} / \mathrm{s}^{2}\right)\end{array}$ & $\begin{array}{c}\text { Left quarter point } \\
\left(\mathrm{m} / \mathrm{s}^{2}\right)\end{array}$ & $\begin{array}{c}\text { Right quarter } \\
\text { point }\left(\mathrm{m} / \mathrm{s}^{2}\right)\end{array}$ \\
\hline Level (IV) & 24.00 & 25.35 & 26.65 \\
\hline Level (III) & 27.54 & 22.66 & 28.37 \\
\hline Level (II) & 31.75 & 33.88 & 25.08 \\
\hline Level (I) & 40.64 & 35.80 & 25.96 \\
\hline
\end{tabular}

\subsection{Crest velocity}

Table 1 represents absolute max velocity of crest points in stream direction corresponding to various reservoir levels. As can be found, raising reservoir levels from I to III leads to decreasing in total velocities, but to sudden increasing from level III to IV. Maximum velocities can be seen at level I as well. The reason can be attributed to free movement of the upper parts of the dam body.

\subsection{Crest acceleration}

Table 2 represents absolute max acceleration of crest points in stream direction. As shown, in the central point the acceleration increases regularly by decreasing reservoir level and it is followed approximately in left quarter point but accelerations remain the same in the right quarter point for all levels except level III where the maximum acceleration has greater value than the rest.

\subsection{Bottom pressure}

Table 3 represents hydrostatic, absolute max of hydrodynamic and total pressures at bottom of the dam body for different reservoir levels. As shown, 
Table 3: Hydrostatic, absolute max of hydrodynamic and total pressures at the base level.

\begin{tabular}{|cccc|}
\hline Level (IV) & $\begin{array}{c}\text { Hydrostatic } \\
\text { pressure(MPa) }\end{array}$ & $\begin{array}{c}\text { Hydrodynamic } \\
\text { pressure(MPa) }\end{array}$ & $\begin{array}{c}\text { Total pressure } \\
(\mathrm{MPa})\end{array}$ \\
\hline Level (III) & 1.647 & 0.357 & 2.005 \\
\hline Level (II) & 1.324 & 0.300 & 1.624 \\
\hline Level (I) & 0.794 & 0.326 & 1.120 \\
\hline
\end{tabular}

absolute max of hydrodynamic pressure in level IV is more than the rest and in level I is less than the others. Between these levels hydrodynamic pressure varies between maximum and minimum amounts and generally, total pressure grows with increasing reservoir level.

\subsection{Cracked areas}

Cracked areas for upstream and downstream faces of the dam body for various water levels are shown in figure 7. In each level two various situations corresponding to static and seismic analyses are shown. As it is found, cracking status of the dam body becomes critical by reservoir dewatering. Generally it is the case for upper parts of upstream and downstream faces, in vicinity of pulvino and some areas around bottom of the dam body. In static condition, cracked areas for levels I, II and III are the same and limited only to a few elements, but in level IV the number of cracked elements show a little increasing. On the other hand, seismic analyses with various reservoir levels shows increase in number of cracked elements and also changes in pattern of cracked areas according to reservoir dewatering.

\section{Conclusion}

In the present paper, effect of reservoir level fluctuation on nonlinear seismic response of a high concrete arch dam is considered. Mass concrete is assumed to able cracking and crushing in tension and compression, respectively. Reservoir medium is assumed compressible and foundation rock is flexible. Four levels are chosen for studying and FE model of dam-reservoir-foundation is excited using an earthquake record scaled based on response spectrum of the dam site. It is found that dewatering the reservoir leads to increasing absolute maximum velocity and acceleration along the crest and moving the crest toward upstream direction.

In addition, when the reservoir is impounded, the number of cracked elements and the extension of cracked regions are less than the cases when the reservoir water level is low. 

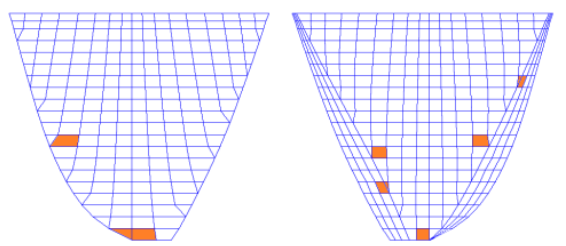

Static Analysis
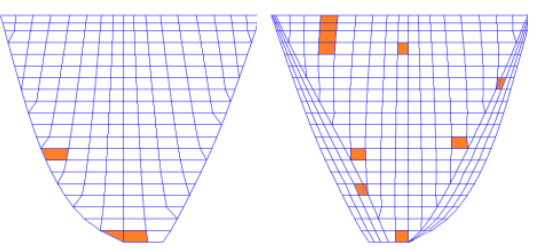

Seismic Analysis

Level IV

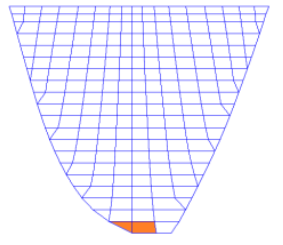

Static Analysis

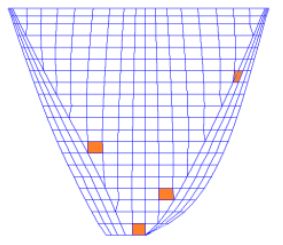

$$
\text { ysis }
$$

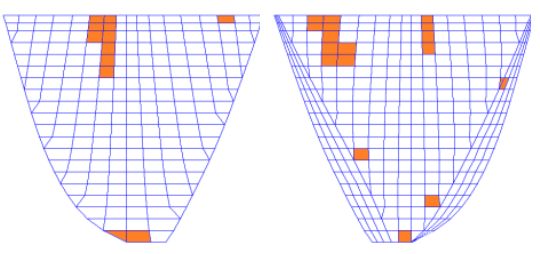

Seismic Analysis

Level III

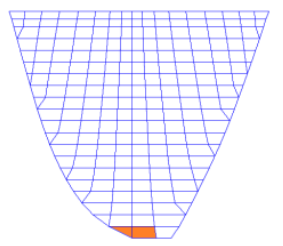

Static Analysis

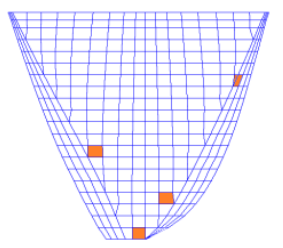

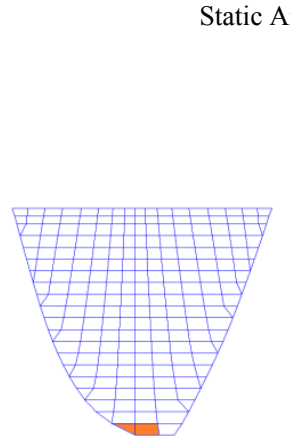

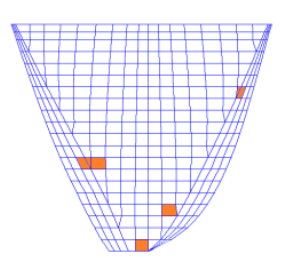

Static Analysis

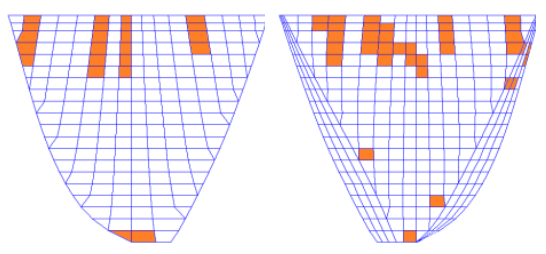

Seismic Analysis

Level II

Figure 7: Cracked areas in upstream and downstream faces of the dam body. 


\section{References}

[1] Chopra, A.K., Hydrodynamic pressures on dams during earthquakes. ASCE: Journal of Engineering Mechanics, 93, 1967.

[2] Chwang, A.T., Hydrodynamic pressures on sloping dams during earthquakes, part 2: exact theory, Journal of Fluid Mechanics, 87(2), 1978.

[3] Fok, K.L. \& Chopra, A.K., Hydrodynamic and foundation flexibility effects in earthquake response of arch dams. Journal of Structural Engineering, 112(8), pp. 1810-1828, 1986.

[4] Hung, T.K. \& Chen, B.F. Non-linear hydrodynamic pressure on dams. ASCE: Journal of Engineering Mechanics. 106(6), pp. 1372-1391, 1990.

[5] Fahjan, Y.M., Borekci, O.S., \& Erdik, M., Earthquake-induced hydrodynamic pressures on a 3D rigid dam-reservoir system using DRBEM and a radiation matrix, International Journal of Numerical Methods in Engineering, 56, pp. 1511-1532, 2003.

[6] Proulx, J., Paultre, P., Rheault, J., \& Robert, Y., An experimental investigation of water level effects on the dynamic behavior of a large arch dam. Earthquake Engineering and Structural Dynamics, 30, pp.1147-1166, 2001.

[7] Akkose, M., Bayraktar, A., Dumanoglu, A.A., Reservoir water level effects on nonlinear dynamic response of arch dams. Journal of Fluids and Structures, 24, pp. 418-435,2008

[8] Kuo, JSH., On the nonlinear dynamic response of arch dams to earthquakes-I. Fluid-structure interaction: Added-mass computations for incompressible fluid. II. Joint opening nonlinear mechanism: Interface smeared crack model. PhD thesis, University of California, Berkeley, 1982.

[9] Hall J.F., Efficient non-linear seismic analysis of arch dams, Earthquake Engineering and Structural Dynamic, 27, pp.1425-1444, 1998.

[10] Espandar, R. \& Lotfi V., Comparison of non-orthogonal smeared crack and plasticity models for dynamic analysis of concrete arch dams, Computers \& Structures, pp. 1461-1474, 2002.

[11] Mirzabozorg, H., Ghaemian M. \& Kianoush M.R., Damage mechanics approach in seismic analysis of concrete gravity dams including damreservoir interaction, European Earthquake Engineering, XVIII(3), pp.1724, 2004.

[12] Mirzabozorg, H., \& Ghaemian M., Nonlinear Behavior of Mass Concrete in Three-dimensional Problems Using Smeared Crack Approach, Earthquake Engineering \& Structural Dynamics, 34, pp.247-269, 2005. 